\title{
PERANCANGAN APLIKASI MOBILE PERTOLONGAN PERTAMA UNTUK KEAMANAN DAN KESELAMATAN LANSIA
}

\author{
Indrajani Sutedja ${ }^{\text {() }}$, Raymond Bahana ${ }^{2)}$ dan Ida Bagus Kerthyayana Manuaba ${ }^{3)}$ \\ ${ }^{1}$ Information Systems Department, School of Information Systems, Bina Nusantara University \\ ${ }^{2,3}$ Computer Science Department, Faculty of Computing and Media, Bina Nusantara University \\ $1,2,3$ Jl. Kyai H. Syahdan No.9, Jakarta, Indonesia 11480 \\ E-mail : indrajani@binus.ac.id ${ }^{1)}$,rbahana@binus.edu ${ }^{2)}$,imanuaba@binus.edu ${ }^{3)}$
}

\begin{abstract}
ABSTRAK
Penelitian untuk pembuatan dan perancangan aplikasi berbasis mobile untuk pertolongan pertama bagi keamanan dan keselamatan lanjut usia, di latar belakangi oleh tingginya tingkat kecelakaan yang dialami oleh penduduk lansia (lanjut usia berumur 50-65 tahun ke atas) di Indonesia. Sangat banyak sekali penduduk lansia di Indonesia yang menjalankan kegiatan atau aktivitas sehari-hari tanpa diawasi secara langsung oleh keluarga dekat mereka maupun wali atau asisten pengawas pribadi, oleh karena itu kemungkinan meningkatnya kasus kecelakaan yang terjadi akibat penurunan fungsi anggota tubuh dikarenakan faktor usia dan fisik semakin tinggi. Hal ini dapat berakibat sangat fatal apabila tidak ada orang ataupun pengawas di sekitar lansia tersebut sehingga tidak adanya tindakan pertolongan pertama secepatnya untuk membantu lansia tersebut yang diakibatkan dari kurangnya pemahaman soal medis atau keterbatasan informasi untuk segera menghubungi pihak rumah sakit terdekat. Pembuatan desain dan perancangan aplikasi ini dikhususkan sementara untuk telepon pintar Android dengan menggunakan cloud server untuk penyimpanan data.
\end{abstract}

Kata Kunci: Aplikasi Mobile, Lansia, Pertolongan Pertam, Gps, Cloud.

\section{PENDAHULUAN}

Di era globalisasi ini, pemahaman dan penggunaan teknologi khususnya telepon pintar (smartphone) ini sudah banyak sekali digunakan oleh semua orang dari berbagai macam golongan. Pengembangan teknologi dari fitur - fitur yang ada apa smartphone pun semakin kompleks dalam penggunaanya dan penerapannya. Penggunaan dari smartphone di era sekarang juga dapat dirasakan manfaatnya untuk menunjang aktivitas seharihari dari penggunanya. Banyak sekali manfaat dari fitur yang ditawarkan oleh telepon pintar, dilihat dari fungsi yang ada dan dapat digunakan mulai dari perangkat keras (hardware) dan sistem pengoperasian serta aplikasi (software).

Aplikasi yang diperlukan pada saat ini tidak hanya terbatas untuk komunikasi jarak jauh maupun sekedar hiburan semata, tetapi juga harus memiliki manfaat yang lebih berguna khususnya di bidang penanganan medis dan pertolongan pertama yang dapat dilakukan sesegera mungkin. Indonesia sendiri memiliki

masalah dalam penanganan keselamatan dan keamanan penduduknya terutama dari golongan lansia (lanjut usia berumur 50-65 tahun ke atas) yang sangat tinggi yang diakibatkan oleh faktor usia dan fisik yang mengalami penurunan sehingga kecelakaan seperti terjatuh saat sedang melakukan aktivitas sehari - hari sering kali terjadi. Hal tersebut akan berakibat fatal apabila tidak ada pengawas di dekat para lansia untuk segera membantu dan menolongnya segera mungkin untuk dilakukan tindakan medis untuk mencegah resiko dari hal-hal yang dapat menjadi masalah kesehatan dan keselamatan jiwa dari lansia tersebut kedepannya.

Ditinjau dari data Kementerian Koordinator Kesejahteraan Rakyat (KESRA) pada tahun 2020 perkiraan penduduk lansia di Indonesia akan mencapai 28,8 juta jiwa dengan perbandingan $11,34 \%$ dari total penduduk yang ada di Indonesia dengan angka usia harapan hidup sebesar 71,1 tahun (Patria, 2018). Kecelakaan jatuh merupakan satu problem yang dihadapi oleh lansia yang dapat menyebabkan tingkat kemandirian dari lansia tersebut berukurang, meningkatnya pengeluaran biaya hidup untuk perawatan dan pengobatan, dan bahkan kematian. Satu dari tiga lansia yang berumur diatas 65 tahun mengalami kecelakaan jatuh tiap tahunnya, 20-30\% mengalami cidera sedang sampai berat yang mengakibatkan adanya gangguan dalam kegiatan dan aktivitas mereka sehari-hari (Ambrose, 2015), dan 25-35 \% lansia mengalami pengalaman jatuh tiap tahunnya. Selain itu, terhitung terakhir dari tahun 2009 ada lebih dari 19,000 lansia yang meninggal dunia diakibatkan oleh kecelakaan jatuh, sehingga jatuh menjadi urutan ke lima yang mengakibatkan kematian pada lansia.

Perancangan dan pengembangan dari aplikasi berbasis mobile untuk lansia ini dapat berguna sebagai alarm / warning yang akan dikirim langsung ke smartphone dari anak atau pengawas dari lansia tersebut. Aplikasi ini juga dapat mengawasi pergerakan dan aktivitas yang di lakukan oleh lansia menggunakan teknologi GPS untuk mengetahui lokasi dari lansia tersebut. Selain itu, apabila lansia mengalami kecelakaan jatuh, telepon pintar yang di 
gunakan akan mengirimkan parameter dari fitur akseletaror sebagai alat pengukur getaran / shock saat telepon pintar tersebut ikut jatuh bersamaan, dari parameter tersebut akan terdeteksi oleh aplikasi untuk segera mengirimkan informasi tersebut kepada pengawas melalui warning yang akan dikeluarkan berupa suara di smartphone milik pengawas, dan apabila tidak ada jawaban dari pengawas selama kurang dari satu menit maka aplikasi akan secara otomatis mengirimkan lokasi dari lansia tersebut ke rumah sakit terdekat. Oleh karena itu, aplikasi ini diharapkan dapat membantu untuk mempercepat proses pemberian pertolongan pertama apabila terjadi kecelakaan jatuh pada lansia, dan juga anak ataupun pengawas mereka jadi lebih tenang saat sedang tidak mengawasi dari dekat.

\section{RUANG LINGKUP}

Lingkup penelitian ini adalah berfokus pada merancang dan membangun aplikasi mobile untuk lansia ini yang dapat berguna sebagai alarm / warning, yang dapat mengirim pesan langsung ke smartphone anak atau pengawas lansia.

\section{BAHAN DAN METODE}

Berikut disajikan kajian teori dan metodologi yang berkaitan dengan penelitian ini.

\subsection{Lansia}

Menurut World Health Organization (WHO), lansia dapat diartikan fase dimana seorang insan memasuki kelompok usia 45-59 tahun (middle age), 60-74 tahun (elderly), 75-90 tahun (old), sampai 90 tahun ke atas (very old) dan telah memasuki tahapan akhir dari fase kehidupannya (Çakir, 2012). Kelompok yang dikategorikan sebagai lansia ini akan terjadi suatu proses yang dinamakan Aging Process atau penuaan, yang mengakibatkan adanya degenerasi dari berbagai fungsi organ tubuh dan persendian yang meningkatkan resiko untuk terserang penyakit menjadi lebih tinggi dikarenakan adanya perubahan struktur dan fungsi sel, jaringan serta sistem organ sehingga berpengaruh pada aktivitas dan kegiatan sehari-hari.

\subsection{Akselerometer dan GPS}

Akselerometer merupakan alat yang dapat mengukur akselerasi secara tepat yang akan menghitung pergerakan atau fenomena secara tiba-tiba dari massa uji (dalam hal ini, lansia) untuk mengukur akselerasi menurut gravitasi ( $\mathrm{g}=9,81 \mathrm{~m} / \mathrm{s} 2$ ) (Putri, 2018; Liandara, 2017).

GPS yang merupakan dari singkatan Global Position System adalah sistem yang dapat digunakan di perangkat mobile untuk menentukan letak di permukaan bumi dengan bantuan penyelarasan sinyal satelit yang dapat digunakan oleh pengguna secara umum yang dinamakan dengan GPS Tracker atau GPS Tracking, yang memiliki fungsi untuk melacak posisi dari device dalam keadaan real-time (Li, 2015).

\subsection{Cloud Computing}

Cloud computing digunakan sebagai media untuk mengolah data yang menggunakan internet sebagai server (Wang, 2010; Furht, 2010). Di dalam pengaplikasian nya di sistem Android sehingga lebih mudah di akses dimanapun dan kapanpun. Penggunaan cloud sebagai server ini memerlukan adanya koneksi internet yang harus terhubung melalui telepon pintar (Gambar 1).

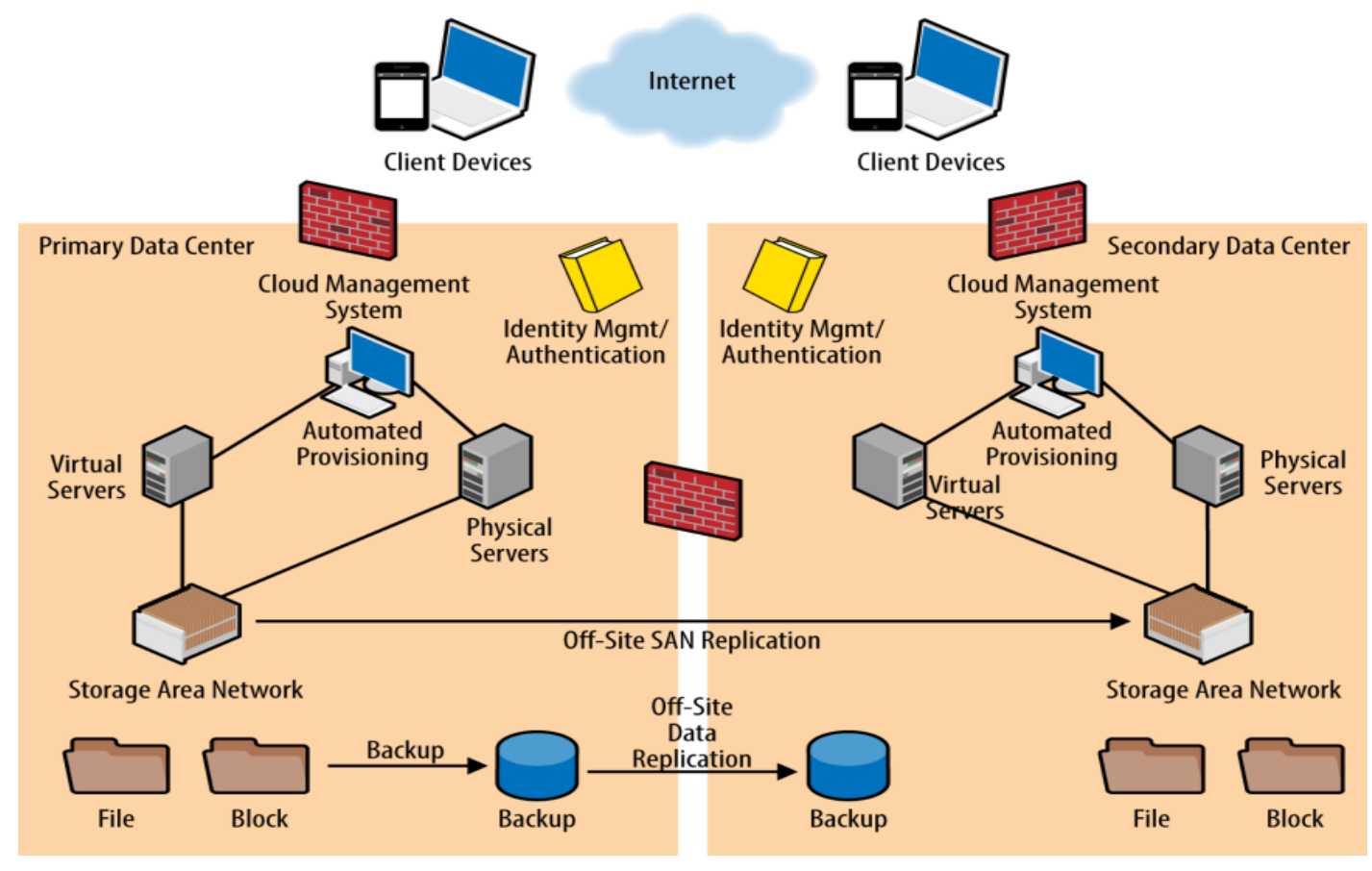

Gambar 1. Arsitektur cloud (Bond, 2015) 


\subsection{Tahapan Penelitian}

Hasil dari penilitian karya ilmiah ini berupa aplikasi mobile yang berfungsi sebagai alat pendeteksi kecelakaan jatuh pada lansia dan mengirimkan pesan kepada anak atau pengawas mereka untuk segera melakukan tindakan secepatnya, jika tidak ada respon apapun maka aplikasi ini juga dapat mengirimkan pesan kepada rumah sakit terdekat dan mengirimkan lokasi dari lansia tersebut untuk segera melakukan pertolongan medis secepatnya.

Proses pendeteksian kejadian jatuh pada lansia tersebut menggunakan fitur sensor akselerator yang dimiliki oleh telepon pintar yang akan terus membaca adanya perubahan akselerasi pada sumbu $\mathrm{x}$, y dan $\mathrm{z}$ dipengaruhi berdasarkan massa dari lansia, gaya, serta percepatan gravitasi $(9,81 \mathrm{~m} / \mathrm{s})$. Metode pengukuran yang dilakukan berdasarkan filter yang diterapkan yaitu low pass filter dan high pass filter berdasarkan penelitian yang dilakukan oleh Bylemans (2009). Dalam penelitian tersebut keadaan terjatuh dikelompokkan menjadi empat kategori yaitu telungkup, tengadah, posisi jatuh ke kiri, dan posisi jatuh ke kanan, dan dibedakan ke dalam tiga sudut kemiringan yang dihitung dari sumbu $\mathrm{x}, \mathrm{y}$, dan $\mathrm{z}$. Penjelasan sudut dapat dilihat pada Tabel 1 dan Tabel 2 untuk sudut minimum dan maksimum.

Persamaan yang akan digunakan menggunakan rumus yang dikemukakan oleh Chen (2011). Menggunakan TA, $\mathrm{A}^{\mathrm{x}}(1), \mathrm{A}^{\mathrm{y}}(2)$, dan $\mathrm{A}^{\mathrm{z}}$ (3) yang menjadi besaran akselerasi dari sumbu $\mathrm{x}, \mathrm{y}$,dan $\mathrm{z}$ melalui high pass filter.

$$
\begin{aligned}
\mathrm{TA}_{\mathrm{x}} & =\operatorname{arcos}\left(\mathrm{A}_{\mathrm{x}} / 9,81 \mathrm{~m} / \mathrm{s}\right) \times(180 / \mathrm{pi}) \\
\mathrm{TA}_{\mathrm{y}} & =\operatorname{arcos}\left(\mathrm{A}_{\mathrm{y}} / 9,81 \mathrm{~m} / \mathrm{s}\right) \times(180 / \mathrm{pi}) \\
\mathrm{TA}_{\mathrm{z}} & =\operatorname{arcos}\left(\mathrm{A}_{\mathrm{z}} / 9,81 \mathrm{~m} / \mathrm{s}\right) \times(180 / \mathrm{pi})
\end{aligned}
$$

Parameter untuk menentukan jatuh atau tidaknya ditentukan dari perubahan akselerasi yang secara cepat dan tiba - tiba dan akan adanya penurunan dari akselerasi apabila massa objek terjatuh / berbaring. Posisi dari objek tersebut juga ditentukan berdasarkan sudut kemiringan yaitu telungkup, tengadah, posisi samping kiri, dan samping kanan. Akan dijelaskan perbedaan sudut antara posisi badan saat berbaring biasa dengan berbaring akibat terjatuh.

Tabel 1. Sudut saat berbaring biasa

\begin{tabular}{|l|c|c|c|}
\hline \multicolumn{1}{|c|}{ Posisi } & $\mathrm{TA}_{\mathrm{x}}$ & $\mathrm{TA}_{\mathrm{y}}$ & $\mathrm{TA}_{\mathrm{z}}$ \\
\hline Berdiri & 90 & 0 & 90 \\
\hline Telungkup & 0 & 90 & 90 \\
\hline Tengadah & 180 & 90 & 90 \\
\hline Samping Kiri & 90 & 90 & 180 \\
\hline Samping Kanan & 90 & 90 & 0 \\
\hline
\end{tabular}

Tabel 2. Sudut saat berbaring akibat terjatuh

\begin{tabular}{|l|c|c|c|c|c|c|}
\hline \multirow{2}{*}{\multicolumn{1}{|c|}{ Posisi }} & \multicolumn{2}{|c|}{$\mathrm{TA}_{\mathrm{x}}$} & \multicolumn{2}{c|}{$\mathrm{TA}_{\mathrm{y}}$} & \multicolumn{2}{c|}{$\mathrm{TA}_{\mathrm{z}}$} \\
\cline { 2 - 7 } & $\min$ & $\max$ & $\min$ & $\max$ & $\min$ & $\max$ \\
\hline Telungkup & 0 & 45 & 75 & 115 & 75 & 115 \\
\hline Tengadah & 140 & 180 & 75 & 115 & 75 & 115 \\
\hline Samping Kiri & 75 & 115 & 75 & 115 & 140 & 180 \\
\hline $\begin{array}{l}\text { Samping } \\
\text { Kanan }\end{array}$ & 75 & 115 & 75 & 115 & 0 & 45 \\
\hline
\end{tabular}

Akselerator akan menentukan sendiri kategori dari kecelakaan jatuh yang terjadi kepada lansia berdasarkan sudut yang ada pada smartphone yang sedang digunakan. Apabila sudut berapa pada titik tertentu, maka aplikasi akan mengeluarkan notifikasi warning kepada anak atau pengawas dari lansia tersebut untuk memastikan keadaan dan kondisinya.

\subsection{Sistem Arsitektur}

Aplikasi ini dikembangkan menggunakan arsitektur sistem Model View Controller (MVC). Model ini digunakan untuk menangani aliran data dalam aplikasi seperti yang ditunjukkan pada Gambar 2.

Gambar 2 terdiri dari komponen-komponen sebagai berikut: User / Pengguna mewakili pengguna lanjut usia yang menggunakan aplikasi ini. Pengguna dapat berinteraksi dengan beberapa fitur yang terdapat pada aplikasi.

Model, yang dikembangkan menggunakan basisdata SQLite, mewakili data dan informasi yang digunakan dalam aplikasi ini. Dalam praktik pemrograman berorientasi objek, model adalah objek yang digunakan untuk mengatur dan mendapatkan data dari basisdata. Komponen model menyimpan data untuk membuat sistem bekerja.

View / Lihat mewakili data yang akan ditampilkan untuk pengguna sebagai Antarmuka Pengguna. Pada bagian ini, data seperti grafik, alert dan riwayat ditampilkan menggunakan komponen Antarmuka Pengguna yang disediakan oleh Android. Karena menggunakan Android sebagai pengembangan, sebagian besar tampilan ditulis dalam Bahasa Markup Ekstra (XML).

Controller / kontroler mewakili logika pemrograman untuk manipulasi data. Sebagai bagian dari arsitektur MVC, kontroler bertindak sebagai penghubung antara pengguna dan model. Ini menangani semua logika pada aplikasi dan menerima permintaan dari pengguna. Kontroler mengambil input dari pengguna kemudian memrosesnya dengan data dari model dan menyediakan output untuk tampilan yang akan ditampilkan kepada pengguna. 
API (Application Programming Interface) adalah perpustakaan perangkat lunak, yang membantu programmer untuk membangun aplikasi perangkat lunak. API memudahkan programmer untuk membuat aplikasi

\subsection{Agile Software Development}

Pengembangan aplikasi ini akan menggunakan Agile framework. Pengembangan dengan Agile software adalah sebuah framework dan praktik yang didasarkan pada nilainilai yang mengutamakan kepuasan pelanggan (Alliance, 2015). Agile software development fokus pada orang yang melakukan pekerjaan dan bagaimana mereka bekerja bersama untuk mencapai tujuan. Ini mengubah cara metode pengembangan piranti lunak tradisional dengan perubahan cepat dan merespons dengan cepat teknologi baru, ide-ide inovatif, inisiatif kompetitif, dan persyaratan dari pengguna.

Ekosistem pengembangan dengan Agile software akan berkembang di masa depan karena dua alasan (Highsmith, 2002). Pertama, sesuai dengan kebutuhan bisnis dengan perubahan cepat. Kedua, karena budaya angkatan kerja di masa depan. Salah satu Agile software development frameworks yang terkenal adalah Scrum. Scrum adalah framework untuk kolaborasi tim yang efektif dan efisien untuk pengembangan sampai dengan pemeliharaan aplikasi yang kompleks (Sutherland, 2013). Fokus pada pengorganisasian diri untuk menghadapi ketidakpastian dan memecahkan masalah yang kompleks. Metodologi Scrum terdiri dari tiga pihak, Pemilik Produk, Scrum Master, dan Tim Pengembang.

Ada tiga bagian penting dalam setiap implementasi Scrum: transparansi, inspeksi, dan adaptasi. Transparansi berarti proses harus terlihat oleh mereka yang bertanggung jawab terhadap hasil. Inspeksi berarti ada yang harus sering memeriksa kemajuan menuju tujuan dari tim untuk mendeteksi sesuatu yang tidak diinginkan. Adaptasi berarti penyesuaian harus dilakukan sesegera mungkin jika pemeriksa menentukan bahwa hasil produk tidak dapat diterima.

\section{PEMBAHASAN}

Disajikan hasil perancangan dan pembahasan dari aplikasi yang dibangun.

\subsection{Aplikasi Tampilan Pengguna}

Gambar 3. merupakan desain tampilan depan dari aplikasi yang akan dirancang. Pada tampilan halaman Dashboard (Gambar 4), terdapat beberapa fitur. Fiturfitur tersebut adalah (1) berfungsi untuk mematikan atau menyalakan aplikasi, hal tersebut diperlukan agar saat pengguna sedang tidak beraktivitas atau sedang tidur, pengguna lansia dapat mematikan aplikasi guna menghemat daya pada telepon pintar; (2) berfungsi sebagai indikator pengukur yang menentukan kondisi dari lansia tersebut seperti nilai berjalan, jika nilai rata-rata yang tampil di Stance berada pada nilai min dan maks seperti pada contoh di Tabel 2, maka aplikasi segera mengirimkan pesan suara maupun push notification kepada pengawas untuk segera memeriksa keadaan lansia tersebut; (3) menampilkan data grafik dari sensor accelerometer yang berfungsi untuk mengukur skala $\mathrm{x}, \mathrm{y}$ dan z sesuai dengan rumus yang berlaku; (4) bagian ini menampilkan indikator status dari pergerakan pengguna lansia tersebut, jika berwarna hijau maka lansia diperkirakan sedang berjalan dengan kecepatan normal, sedang duduk, ataupun aktivitas lainnya yang tidak membahayakan. Apabila berubah menjadi warna merah, maka aplikasi akan otomatis memberikan alert kepada anak atau pengawas dari lansia tersebut.

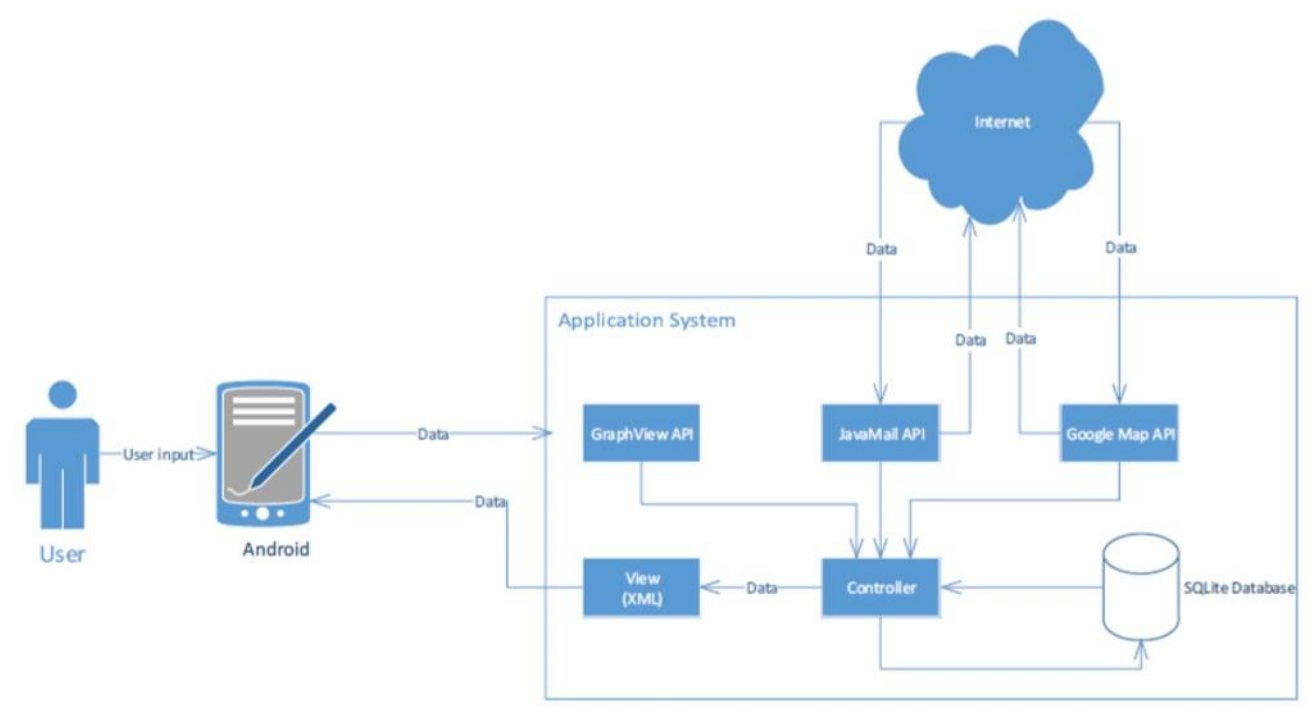




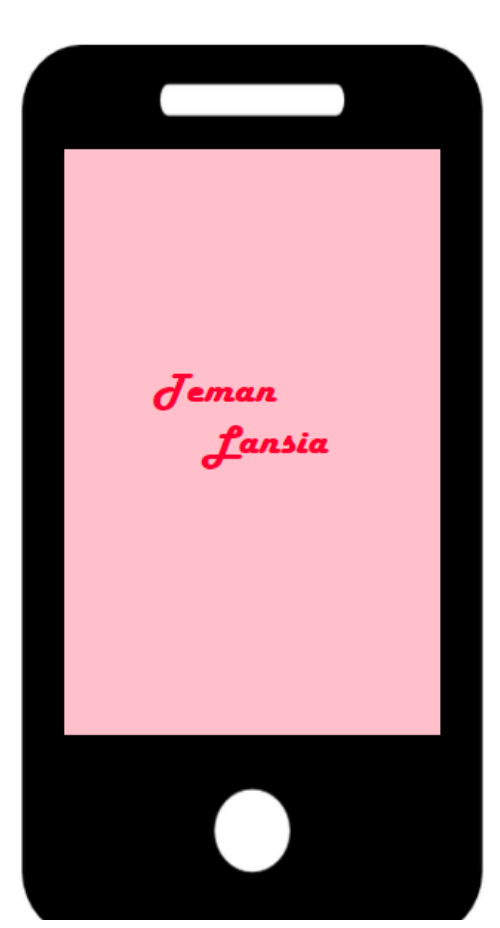

Gambar 2. Arsitektur sistem

terjatuh, maka tampilan yang akan muncul di aplikasi anak atau pengawas yang akan mengeluarkan suara dan getar terus menerus dari telepon pintar mereka disertai dengan push notification.

Di dalam tampilan halaman Alert ada beberapa fitur. Fitur-fitur tersebut adalah (1) merupakan tombol "see maps" untuk mengetahui informasi dari lokasi terakhir dari telepon pintar yang digunakan oleh pengguna lansia tersebut disertai dengan koordinat agar memudahkan pengawas untuk menggunakan aplikasi Maps yang terpasang pada telepon pintarnya; [2] memiliki tombol "Call your's elder" yang berfungsi untuk segera memanggil pengguna lansia untuk memastikan keadaan dari kecelakaan yang dialaminya, apabila tidak ada jawaban atau diperkirakan pengguna lansia tersebut mengalami hilang kesadaran, maka pengawas dapat menggunakan tombol "Ambulance" yang berarti pengawas akan mengirimkan informasi dari lokasi kejadian kecelakaan jatuh pengguna lansia tersebut kepada rumah sakit yang berada di dekat lansia agar dapat segera diberikan pertolongan pertama.

Gambar 3. Tampilan halaman depan
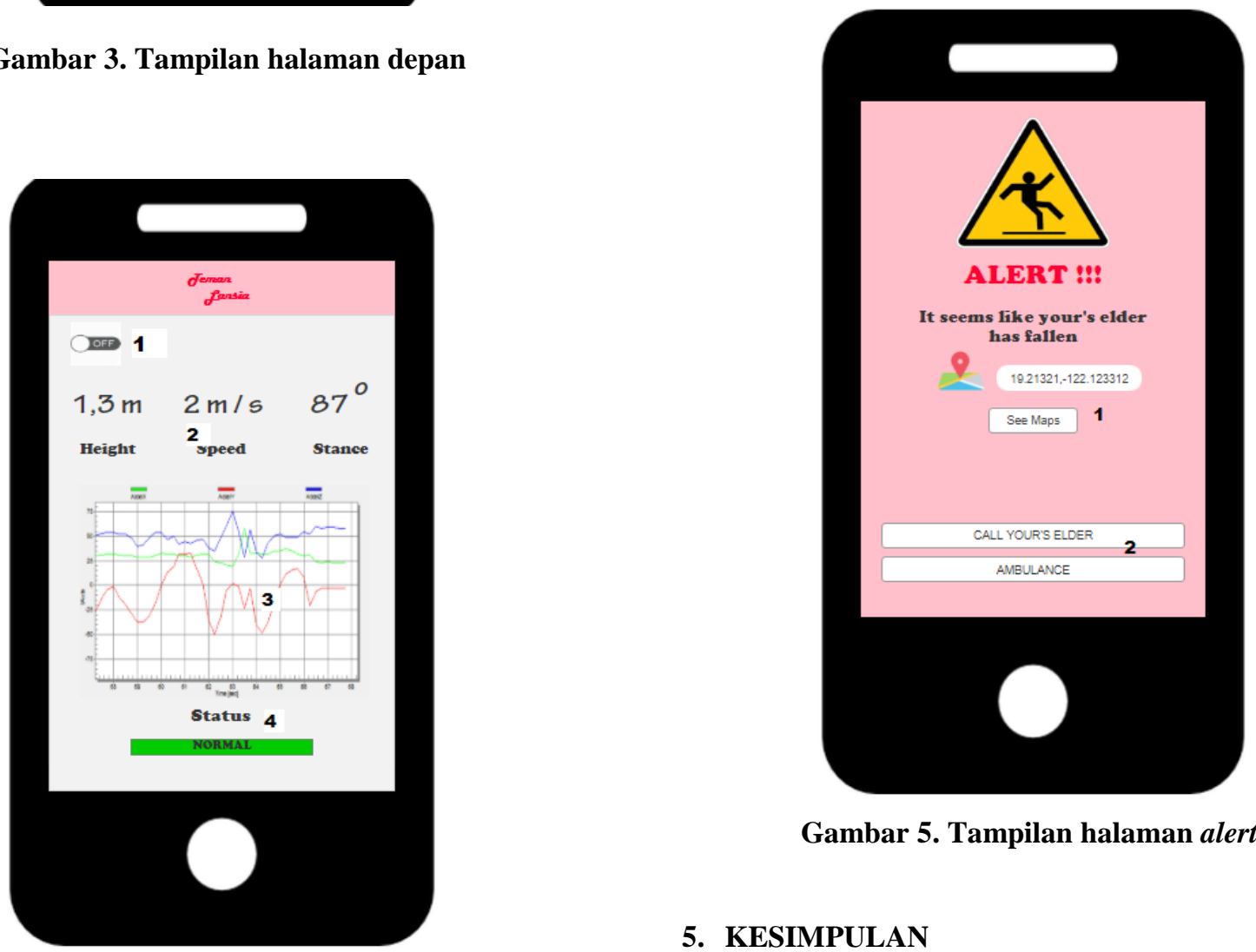

Gambar 5. Tampilan halaman alert

\section{Gambar 4. Tampilan halaman dashboard}

Tampilan pada Gambar 5 merupakan menu Alert yang akan muncul apabila ada indikator yang terpenuhi dari tampilan halaman Dashboard yang menyatakan bahwa kondisi pengguna lansia tersebut mengalami kecelakaan 
kematian pada lansia yang disebabkan oleh kecelakaan jatuh tanpa adanya pertolongan secara cepat dan tepat. Pengguna aplikasi ini (lansia dan pengawas) juga dapat menghubungi pihak rumah sakit terdekat jika terjadi masalah medis yang harus segera ditangani secepatnya disertai dengan fitur GPS yang akan mempermudah pihak rumah sakit untuk menemukan lokasi kecelakaan tersebut.

\section{SARAN}

Penelitian selanjutnya mengenai pembuatan dan perancangan sistem aplikasi untuk lansia ini akan lebih berfokus kepada penggunaan sensor akselerator yang dapat membedakan antara jatuh dan tidak secara lebih detail dan tepat lagi, sehingga tidak ada kesalahan informasi yang tidak diperlukan.

\section{DAFTAR PUSTAKA}

Alliance, A., 2015. Agile 101. Viitattu, 11, p.2015.

Ambrose, A.F., Cruz, L. and Paul, G., 2015. Falls and fractures: a systematic approach to screening and prevention. Maturitas, 82(1), pp.85-93.

Bond, J., 2015. The enterprise cloud: Best practices for transforming legacy IT. " O'Reilly Media, Inc.".

Bylemans, I., Weyn, M. and Klepal, M., 2009, October. Mobile phone-based displacement estimation for opportunistic localisation systems. In 2009 Third International Conference on Mobile Ubiquitous Computing, Systems, Services and Technologies (pp. 113-118). IEEE.

Çakir, Ö., 2012. Accessibility of Information Technologies in the Resting Home. International Journal of Computer Science \& Information Technology, 4(6), p.1.
Furht, B. and Escalante, A., 2010. Handbook of cloud computing (Vol. 3). New York: Springer.

Highsmith, J.A. and Highsmith, J., 2002. Agile software development ecosystems. Addison-Wesley Professional.

Li, X., Zhang, X., Ren, X., Fritsche, M., Wickert, J. and Schuh, H., 2015. Precise positioning with current multi-constellation global navigation satellite systems: GPS, GLONASS, Galileo and BeiDou. Scientific reports, 5, p.8328.

Liandana, M., Putra, M.A.W. and Aryanto, K.A.A., 2017. Deteksi Posisi Tubuh pada Aktivitas Pengguna Smartphone Menggunakan Sensor Accelerometer. E-Proceedings KNS\&I STIKOM Bali, pp.630-633.

Pamty Freedson, D.P. and Janz, K.F., 2005. Calibration of accelerometer output for children. Med. Sci. Sports Exerc, 37, pp.S523-S530.

Patria, A.S. and Mutmainah, S., 2018. Model Pemberdayaan Kelompok Lanjut Usia Wanita Melalui Industri Kreatif. E-Dimas: Jurnal Pengabdian kepada Masyarakat, 9(1), pp.15-27.

Putri, T.D., Sugeng, W. and Srikandi, B.C.A., 2018. Perbaikan Kualitas Tidur Berdasarkan Posisi Tubuh Saat Tidur Menggunakan Body Position Sensor. Sebatik, 22(2), pp.194-201.

Sutherland, J. and Schwaber, K., 2013. The scrum guide. The definitive guide to scrum: The rules of the game. Scrum. org, 268.

Wang, L., Von Laszewski, G., Younge, A., He, X., Kunze, M., Tao, J. and Fu, C., 2010. Cloud computing: a perspective study. New Generation Computing, 28(2), pp.137-146. 